\title{
AVALIAÇÃO DO AMBIENTE SINÓTICO DE UM BOW ECHO EM 29 DE MAIO DE 2013 NO RIO GRANDE DO SUL: UM EPISÓDIO DE DERECHO?
}

\author{
Maurício I. Oliveira, Diogo. M. Custodio, Ernani L. Nascimento \\ Departamento de Física - UFSM - Santa Maria, RS - Brasil \\ mauricio.meteorologia@gmail.com
}

RESUMO: Na manhã de 29 de maio de 2013 uma tempestade do tipo bow echo causou danos significativos em uma ampla área geográfica entre os setores oeste e central do Rio Grande do Sul. O ambiente em escala sinótica conducente à atividade convectiva é investigado neste trabalho. A semelhança entre alguns padrões dinâmicos e a extensão e duração dos danos observados indica a possibilidade de classificar este evento como um derecho.

ABSTRACT: On the morning of May 29, 2013, a bow echo thunderstorm caused significant damage over a wide geographical area between the west and central areas of Rio Grande do Sul state. The synoptic scale environment leading to convective activity is investigated in this work. The similarity between some dynamic patterns and the extent and duration of observed damage indicates the possibility of this event to be classified as a derecho.

\section{INTRODUÇÃO}

Durante a manhã do dia 29 de maio de 2013 uma intensa linha de instabilidade na forma de arco (bow echo) deslocou-se entre as regiões oeste e central do Rio Grande do Sul (RS), provocando uma extensa faixa de danos em sua trajetória devido a intensas rajadas de vento. Algumas estações automáticas do INMET registraram rajadas acima de $100 \mathrm{~km} / \mathrm{h}$. Neste trabalho é conduzida uma avaliação do ambiente sinótico associado a este evento de tempo severo e é especulada a possibilidade de caracterizar este episódio como um evento de derecho.

\section{MATERIAIS E MÉTODOS}

O ambiente sinótico conducente ao evento de tempo severo é investigado através da análise de "ingredientes atmosféricos" necessários para formação de tempestades convectivas em 
latitudes médias (BROOKS e ANDERSON, 2004). Foram utilizadas as análises do modelo GFS do NCEP com $1^{\circ}$ resolução espacial, imagens do radar meteorológico de Santiago e do satélite GOES-12, dados de estações automáticas de superfície (EAS) do INMET e sondagens atmosféricas lançadas pela Base Aérea de Santa Maria (SBSM).

\section{RESULTADOS}

A análise do modelo GFS das $12 Z$ do 29/05 em médios e altos níveis da troposfera (Figs. 1a e 1b) indicou a presença de um amplo cavado sobre a região da Bacia do Prata e associada ciclôgenese em superfície (Fig. 1c) na fronteira entre o RS e Uruguai. Ar quente e úmido

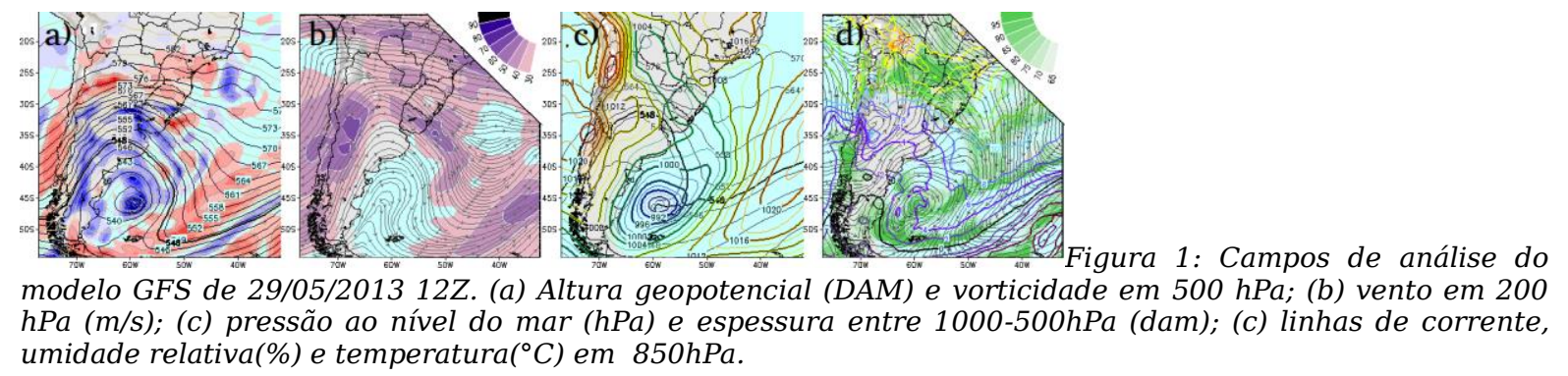

abastecia a região na forma de Jato de Baixos Níveis (JBN) (Fig. 1d).

Ao avançar sobre o RS, a frente fria agiu como mecanismo de disparo convectivo e diversas tempestades formaram-se ao longo e na dianteira deste sistema, como observa-se nas imagens realçadas do canal infravermelho do satélite GOES-12 (Fig. 2a). De forma geral, os parâmetros de instabilidade condicional apresentaram valores baixos a moderados nos setores oeste e central do estado, situação observada na sondagem atmosférica de Santa Maria das $12 Z$ (Fig. 2b). Adicionalmente, os valores de cisalhamento vertical do vento nos primeiros 6km (não mostrados) eram altos na maior parte do RS e, em geral, estão de acordo com os limiares tipicamente presentes em ambientes conducentes à ocorrência de tempo convectivo severo em médias latitudes (BROOKS e ANDERSON, 2004). 


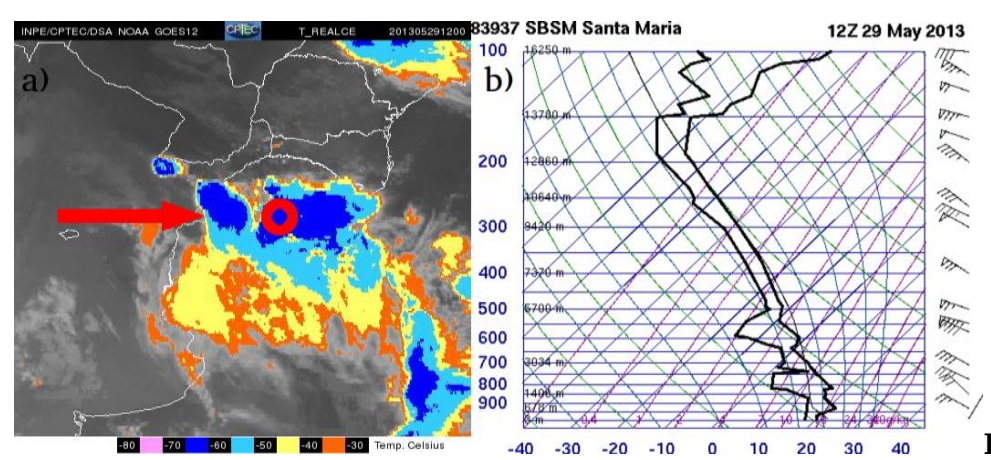

canal infravermelho do satélite GOFS 12 de 29/05/2013 127 . A sealçada do em evolução e o círculo a região da radiossondagem analisada. (b) Diagrama Sket-T da radiossondagem lançada no dia 29/05/2013 $12 \mathrm{Z}$ em Santa Maria, RS. Fonte: CPTEC/INPE e Universidade de Wyoming (respectivamente)

A linha de instabilidade formou-se na Argentina e rapidamente avançou pelo RS. Ao atingir a região central do RS, entrou em modo bow echo (JOHNS e HIRT, 1987), mais evidentemente visto nas imagens do radar de Santiago (Fig. 3). Diversos danos a residências, redes elétricas e árvores tombadas foram reportados em cidades na trajetória da tempestade.

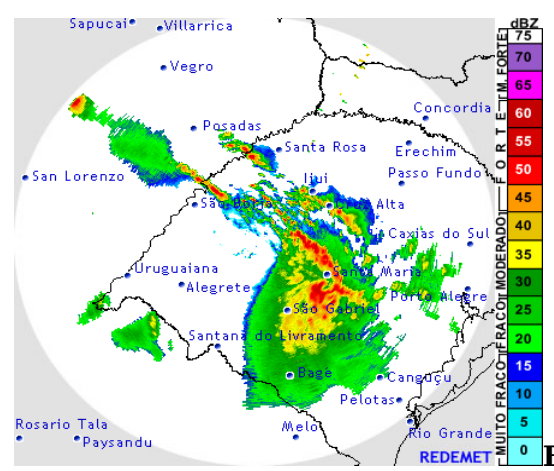
meteorológico de Santiago/RS déco Aeronáutica (ht.tn://www.redemet.aer.mil.br)

Diversas EASs ao registraram rajadas severas ou marginalmente severas.

A longa duração e a grande extensão geográfica afetada pelos ventos intensos sugerem a possibilidade de se caracterizar este episódio como um derecho (JOHNS e HIRT, 1987). O ambiente sinótico reinante durante o período em que se deu a atividade convectiva possui diversas semelhanças com padrão dinâmico serial descrito por Johns e Hirt (1987), tais como a presença de um ciclone extratropical em superfície e associada frente fria, assim como intenso escoamento em níveis médios. Para melhor avaliar esta hipótese, uma análise mais detalhada dos dados de velocidade do vento e danos em superfície se faz necessária.

\section{CONCLUSÃO}

O episódio de bow echo ocorrido no dia 29/05/2013, responsável por causar danos nas regiões oeste e central do RS, desenvolveu-se ao longo de uma frente fria em superfície em 
um ambiente com valores marginais de instabilidade condicional, porém com intenso cisalhamento nos primeiros 6000 metros da troposfera. Isto enfatiza uma importante contribuição da forçante sinótica.

A possível classificação deste episódio como um derecho através dos critérios definidos por (JOHNS e HIRT, 1987) ainda carece de uma análise mais robusta de dados de vento das EASs, METAR e danos registrados ao longo da trajetória da tempestade. Este caso continua a ser estudado e novos resultados serão apresentados em trabalhos futuros. Em caso de confirmação, este poderá ser o primeiro caso documentado de um derecho na América do Sul.

\section{REFERÊNCIAS}

BROOKS, H. E.; ANDERSON, A. R. Climatological aspects of convective parameters from NCAR/NCEP Reanalysis In: Preprints 22 Conference on Severe Local Storms, Hyannis, EUA, Amer. Met. Soc., em mídia digital, 2004. Anais eletrônicos... (Disponível em http://ams.confex.com/ams/aram22sls/techprogram/paper_81585.htm).

JOHNS, R. H.; HIRT, W. D. Derechos: widespread convectively induced windstorms. Wea. Forecasting., v. 2,p. 32-49, 1987. 